\title{
Solution-Grown Zn/Al Layered Double Hydroxide Nanoplatelets onto Al Thin Films: Fine Control of Position and Lateral Thickness
}

\author{
D. Scarpellini, ${ }^{1}$ C. Leonardi, ${ }^{1}$ A. Mattoccia, ${ }^{1}$ L. Di Giamberardino, ${ }^{1}$ \\ P. G. Medaglia, ${ }^{1}$ G. Mantini, ${ }^{2}$ F. Gatta, ${ }^{2}$ E. Giovine, ${ }^{3}$ V. Foglietti, ${ }^{4,5}$ C. Falconi, ${ }^{2}$ \\ A. Orsini, ${ }^{2,5}$ and R. Pizzoferrato ${ }^{1}$ \\ ${ }^{1}$ Department of Industrial Engineering, University of Rome Tor Vergata, 00133 Rome, Italy \\ ${ }^{2}$ Department of Electronic Engineering, University of Rome Tor Vergata, 00133 Rome, Italy \\ ${ }^{3}$ IFN, National Research Council (CNR), 00156 Rome, Italy \\ ${ }^{4}$ SPIN, National Research Council (CNR), University of Rome Tor Vergata, 00133 Rome, Italy \\ ${ }^{5}$ DICII, University of Rome Tor Vergata, 00133 Rome, Italy \\ Correspondence should be addressed to C. Falconi; falconi@eln.uniroma2.it
}

Received 17 December 2014; Revised 5 April 2015; Accepted 5 April 2015

Academic Editor: Joydeep Dutta

Copyright (C) 2015 D. Scarpellini et al. This is an open access article distributed under the Creative Commons Attribution License, which permits unrestricted use, distribution, and reproduction in any medium, provided the original work is properly cited.

We have grown nanostructured films of $\mathrm{Zn} / \mathrm{Al}$ Layered Double Hydroxide (LDH) on different substrates by combining the deposition of an aluminum micropatterned thin layer with a successive one-step room-temperature wet-chemistry process. The resulting LDH film is made of lamellar-like nanoplatelets mainly oriented perpendicular to the substrate. Since the aluminum layer acts as both reactant and seed for the synthesis of the $\mathrm{LDH}$, the growth can be easily confined with submicrometric-level resolution (about $\pm 0.5 \mu \mathrm{m}$ ) by prepatterning the aluminum layer with conventional photolithographic techniques. Moreover, we demonstrate real-time monitoring of the $\mathrm{LDH}$ growth process by simply measuring the resistance of the residual aluminum film. If the aluminum layer is thinner than $250 \mathrm{~nm}$, the morphology of LDH nanoplatelets is less regular and their final thickness linearly depends on the initial amount of aluminum. This peculiarity allows accurately controlling the LDH nanoplatelet thickness (with uncertainty of about $\pm 10 \%$ ) by varying the thickness of the predeposited aluminum film. Since the proposed growth procedure is fully compatible with MEMS/CMOS technology, our results may be useful for the fabrication of micro-/nanodevices.

\section{Introduction}

Layered Double Hydroxides (LDHs), also known as hydrotalcite-like compounds, are a class of ionic lamellar materials belonging to the group of the anionic clays [1-4]. As shown in Figure 1, LDHs have a lattice structure composed by the stacking of positively charged brucite-shaped layers, consisting of a divalent metal ion $\mathrm{M}^{2+}$ (e.g., $\mathrm{Ca}^{2+}, \mathrm{Zn}^{2+}, \mathrm{Mg}^{2+}$, and $\mathrm{Ni}^{2+}$ ), octahedrally surrounded by six $\mathrm{OH}^{-}$hydroxyl groups. The substitution of the $\mathrm{M}^{2+}$ metal with a trivalent $\mathrm{M}^{3+}$ cation gives rise to the periodic repetition of positively charged sheets (lamellas) alternating with charge-counterbalancing $\mathrm{A}^{n-}$ ions. Furthermore, depending on the synthesis technique and the used precursors, the net positive charge is compensated by the intercalation of $\mathrm{A}^{n-}$ anions (such as hydroxyl groups, nitrates, carbonates, and sulfates) placed in the hydrated interlamellar galleries. Due to this large variety of elements and ions allowed in the crystal, LDHs are a very interesting and rich class of ionic lamellar materials whose general formula may be written as [1-4]

$$
\left[\mathrm{M}_{1-x}{ }^{2+} \mathrm{M}_{x}^{3+}(\mathrm{OH})_{2}\right]^{x+}\left[\mathrm{A}_{x / n}^{n-} \cdot y \mathrm{H}_{2} \mathrm{O}\right]^{x-} .
$$

Most importantly, even quite complex molecules (inorganic or organic compounds, drugs, bioactive molecules, etc.) can be accommodated in the interlamellar template, both during the synthesis itself, with the assembling of a functionalized host-guest LDH composite, and afterwards when 


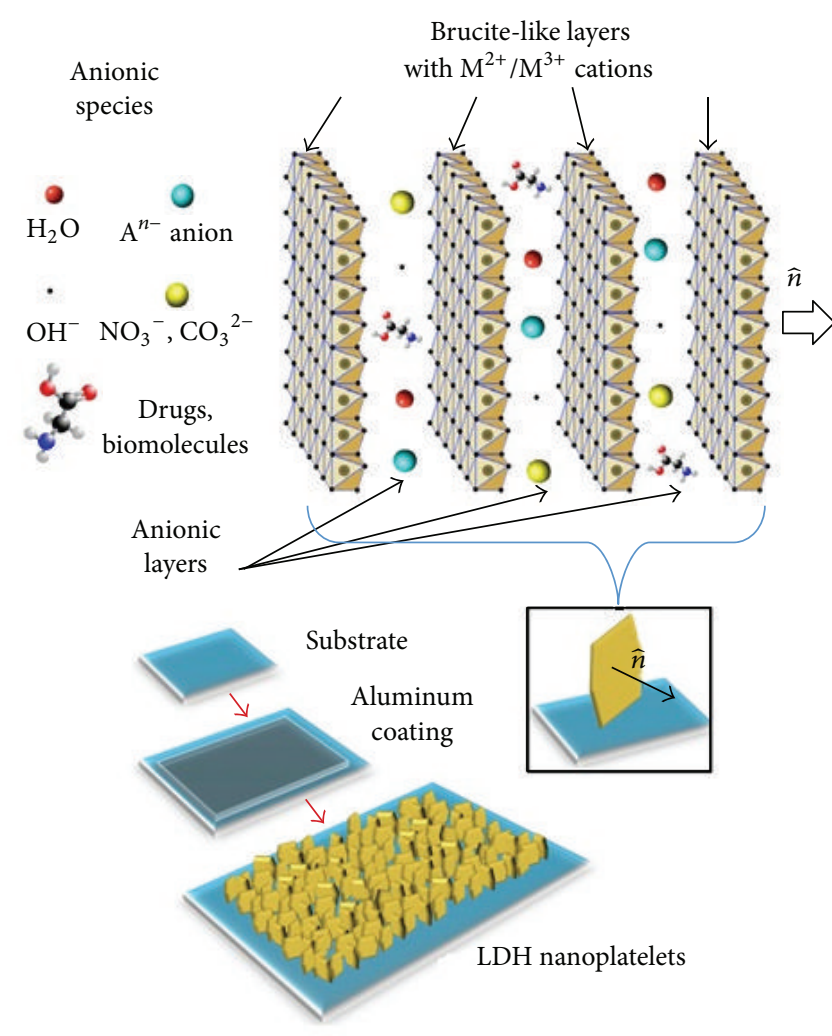

FIGURE 1: Structure and synthesis procedure for solution-growth LDH. The nanoplatelets mostly grow with the anionic layers perpendicular to the substrate. Some possible anionic hosts in the interlamellar space are indicated.

the material is surrounded by and can exchange specific species with the environment. Such peculiar features make LDHs very suitable for a number of applications in different fields, ranging from physical/chemical sensors $[5,6]$ to adsorbents in water purification and liquid waste treatment [7] or catalytic removal of soot and $\mathrm{NO}_{x}$ in vehicle engine exhausts [8], including smart composite materials for optical switching/storage [9] and NIR-emitting quantum code [10]. In addition, the guest molecules can be released in the environment when certain conditions are met, which is promising for self-healing protective coatings which can release the corrosion inhibitors only in aggressive environments [11, 12] and catalyst layers in metal-air batteries [13]. As a most fascinating example, intercalating biological anions may result in LDHs acting as nanocages for sophisticated drugs or genetic material to be delivered inside the patient's body [1-4].

In such applications, a reliable adhesion of LDH films to different substrates is the first requirement. In addition, tuning of the lamellar and nanostructure dimensions would be most advantageous, in order to control the intercalation and release of guest molecules as well as the real interaction with the environments. Finally, the practical fabrication of functional microdevices would require the control of growth localization at a microscopic level on specific areas, that is, according to predetermined micropatterns.
The abovementioned conditions are not met with the usual hydrothermal coprecipitation method [14] for preparation of LDHs. In fact, the addition of a base to a water solution containing the salts of two different metals, $\mathrm{M}^{2+}$ and $\mathrm{M}^{3+}$ of formula (2), causes the precipitation of the metal hydroxides and the formation of $\mathrm{LDH}$ anywhere in the solution. Though the nanoscale precipitates can eventually be collected and then deposited on any substrates, achieving a specific pattern and a good adhesion of the precipitated nanostructures is not simple, which is detrimental for practical applications [15].

By using an alternative, simple, one-step technique, two groups $[16,17]$ first demonstrated the possibility of growing very stable films of LDH well-formed nanoplatelets, in particular $\mathrm{Zn} / \mathrm{Al} \mathrm{LDHs}$, onto aluminum surfaces by immersing aluminum thick foils in a water solution of zinc nitrate or acetate. Unlike the usual hydrothermal growth, only a single salt is dissolved in the growth solution to provide the divalent metal $\mathrm{Zn}^{2+}$, while the trivalent one $\left(\mathrm{Al}^{3+}\right)$ is provided by the aluminum foil that thus acts as both reactant and substrate, in this way greatly improving the adhesion. This method was successively extended to LDHs with various compositions, namely, $\mathrm{Mg} / \mathrm{Al}$ [18], $\mathrm{Ni} / \mathrm{Al}$ [19], and $\mathrm{Cu} / \mathrm{Al}$ [20], on different metals such as $\mathrm{Al}, \mathrm{Zn}, \mathrm{Cu}$, and even $\mathrm{Zn}$ - $\mathrm{Al}$ alloy [21], thus demonstrating that the growth of $\mathrm{LDH}$ nanoplatelets can be achieved on any material that can be coated with $\mathrm{Al}$, $\mathrm{Zn}$, or $\mathrm{Cu}$. Within this framework, we recently achieved [22] the growth of regular LDH nanoplatelets on Al-coated silicon and investigated how the thickness of the reacting aluminum layer influences the morphology, dimensions, and composition of the LDH nanostructures. The sacrificing role of the metal layer was pointed out and we found a lower limit of the coating thickness below which the growth of $\mathrm{LDH}$ nanoplatelets is not regular while $\mathrm{ZnO}$ nanorods take place due to the stoichiometric unbalance [22].

In this work we take advantage of a predeposited aluminum layer for demonstrating the submicrometric control of both the position (about $\pm 0.5 \mu \mathrm{m}$ ) and the thickness (about $\pm 10 \%)$ of the nanoplatelets in a LDH film with a reasonably good adhesion to the substrate by combining the online monitoring of the residual aluminum layer resistance, conventional photolithographic techniques, and wet-chemical growth; the proposed method is general and, as a proof of concept, we show the accurate control of LDH nanoplatelets grown on patterned tracks on different substrates, namely, glass and silicon (111).

\section{Experimental Details}

LDH films were grown on different aluminum-coated substrates, namely, BK-7 glass plates obtained from microscope slides, single-crystal silicon (111) of size $10 \times 10 \mathrm{~mm}^{2}$ cut from $2^{\prime \prime}$ wafers (purchased by Siltronix, thickness 500 microns). The aluminum coatings were deposited by using an e-gun evaporator for tilted evaporation (Balzers 510 system) with different values of thickness for each type of substrate: 10 , $25,50,100,250$, and $300 \mathrm{~nm}$. For the implementation of the aluminum microresistors, the aluminum film was patterned by conventional photolithographic techniques in order to 


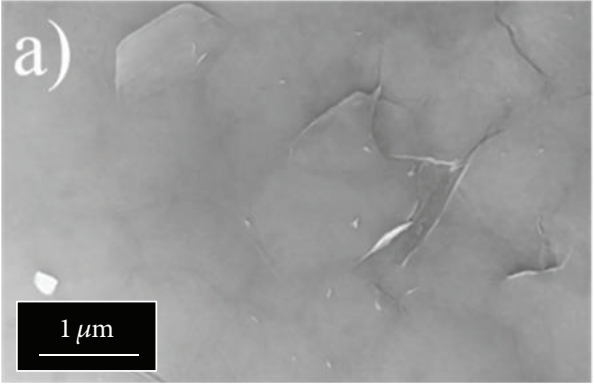

(a)

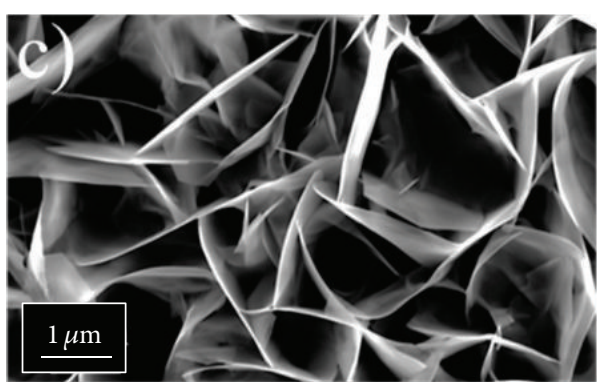

(c)

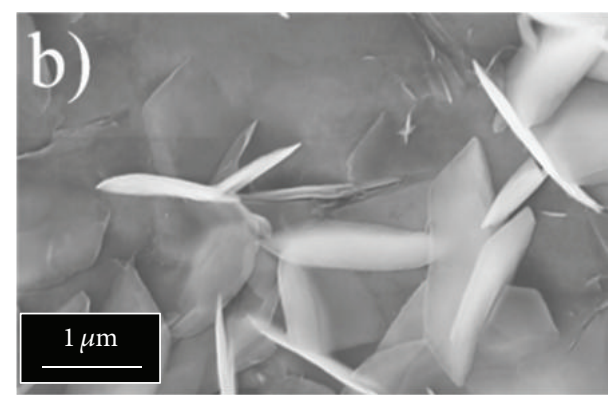

(b)

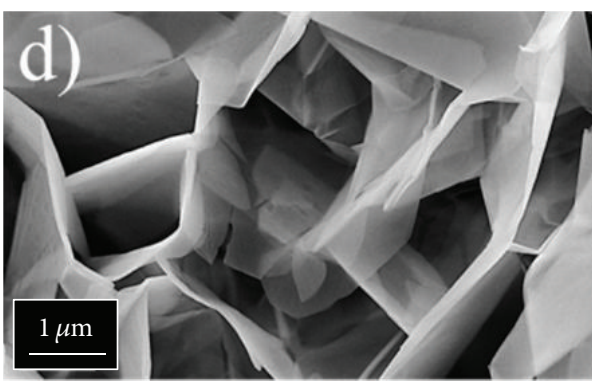

(d)

FIGURE 2: SEM images of the LDH nanoplatelets formed on an aluminum layer with a thickness of $300 \mathrm{~nm}$ on silicon substrate with different growth times: (a) 15 minutes, standard region; (b) 15 minutes, overdeveloped region; (c) 1 hour; (d) 12 hours.

create aluminum microtracks with different aluminum thickness on insulating glass plates of size $20 \times 20 \mathrm{~mm}^{2}$. In order to provide an ideally infinite source of aluminum, we directly used as growth substrates aluminum SEM stubs (Agar Scientific G301). After the aluminum layer deposition, as shown in Figure 2, the hydrothermal growth of LDH was carried out by using a nutrient solution composed of a 1:1 ratio of zinc nitrate hexahydrate $\left(\mathrm{Zn}\left(\mathrm{NO}_{3}\right)_{2} 6 \mathrm{H}_{2} \mathrm{O}\right)$ and hexamethylenetetramine $\left(\mathrm{C}_{6} \mathrm{H}_{12} \mathrm{~N}_{4}\right)$ at $5 \mathrm{mM}$ concentration.

Hexamethylenetetramine was used as a $\mathrm{pH}$ regulator to control the solution [23] basicity through the hydrolyzation and release of ammonia at high temperature. During the growth, the samples were kept in the middle of the solution bottle, anchored to a $45^{\circ}$ tilted Teflon substrate by means of Teflon screws in order to avoid any possible contamination. The growth temperature was fixed at $75^{\circ} \mathrm{C}$, while the growth time was varied from 20 minutes to 12 hours. The sample was cooled down both inside the nutrient solution and in ambient atmosphere (without appreciable differences of results) and then washed with acetone and ethanol at room temperature to remove the residuals on the top of the $\mathrm{LDH}$ surface.

The crystallinity of deposited LDH was evaluated by X-ray diffraction (XRD) carried out by using a RIGAKU diffractometer equipped with a $\mathrm{Cu}$ anode to generate $\mathrm{Cu}$ $\mathrm{K} \alpha$ radiation $(\lambda=1.5406 \AA)$. Each diffraction pattern was collected in the $2 \theta$ range of $10-50^{\circ}$, with a step size of $0.05^{\circ}$ and a count time of $2.0 \mathrm{~s} / \mathrm{step}$. FE-SEM (LEO SUPRA 1250, Oberkochen, Germany) and energy dispersion X-ray spectroscopy (EDS, INCA Energy 300, Oxford Inc., Abingdon, UK) were used to investigate the morphology and elemental composition, respectively.
The resistance measurements were performed by laterally attaching two insulated copper wires to the aluminum thin film with a conductive adhesive silver paste and then covering the contact area with a silicone paste. For the resistance measure, we used an Agilent 34410A multimeter remotely controlled by MATLAB software and USB cable.

\section{Results and Discussion}

First, we present and discuss our results about the dynamics of formation of the LDH film onto the aluminum thin film by considering the SEM images of Figure 2, taken with different growth times. At an early stage of growth, $\mathrm{LDH}$ hexagonal nanoplatelets lay horizontally on the aluminum layer, as shown in Figure 2(a), forming a compact layer of $\mathrm{LDH}$ over the substrate surface. It is possible to see the borders between the different already-formed LDH crystals (lighter areas) which are separated by darker channels, possibly corresponding to thinner LDH regions with a greater absorption of electrons. In the top left area of Figure 2(a) one of the LDH hexagonal plates has partially left its horizontal position to rise above the substrate. In the same sample, an area with a more advanced stage of growth can be identified (Figure 2(b)) where many platelets stand completely perpendicular to the surface. This indicates that the nanoplatelets, after detaching from the surface as partial hexagons, begin to grow perpendicular to the surface, likely because of balance of electrostatic forces. The detached LDH platelets are whiter because of their insulating properties and the greater distance from the aluminum layer. Figures 2(c) and 2(d) demonstrate that the LDH thin film takes around 1 hour to reach the typical 
"cabbage-like" morphology [16, 22, 24, 25], with well-defined lamellar-like nanoplatelets (see Figure 2(c)), and remains substantially unchanged for longer times (Figure 2(d)).

We have also real-time monitored the progressive consumption of the aluminum film, due to the reaction with the nutrient solution and the growth of LDH nanoplatelets, by measuring the electrical resistance of an aluminum microtrack deposited on an insulating glass substrate as a function of the immersion time (see Figure 3). In fact, in contrast with most solution-growth processes, whose realtime monitoring is very challenging [26-29], we suggest that the online monitoring of our process is extremely simple and can give a direct insight into the aluminum migration into the $\mathrm{LDH}$ film. In fact, the electrical resistivity of the $\mathrm{LDH}$ film and of the ions in solutions is much larger than the extremely low resistivity of aluminum; as a result, the value of the total resistance is largely dominated by the residual aluminum layer: $R_{\text {Meas }}=R_{\mathrm{Al}} / / R_{\mathrm{LDH}} / / R_{\mathrm{Sol}} \cong R_{\mathrm{Al}}$.

Therefore, if we consider a constant rate of aluminumion migration from the metal thin film to the forming $\mathrm{LDH}$ nanoplatelets, it is possible to model the aluminum track resistance according to the following formulas:

$$
\begin{aligned}
R_{\mathrm{Al}}\left(t<t_{0}\right)= & R_{\mathrm{cont}}+\rho_{\mathrm{Al}} \cdot \frac{l_{\text {in }}}{w_{\text {in }} \cdot \mathrm{th}_{\mathrm{in}}}, \\
R_{\mathrm{Al}}\left(t>t_{0}\right)= & R_{\mathrm{cont}}+\rho_{\mathrm{Al}} \cdot \frac{l_{\text {in }}}{w_{\text {in }}(t) \cdot \mathrm{th}_{\mathrm{Al}}(t)} \\
\cong & R_{\mathrm{cont}}+\rho_{\mathrm{Al}} \\
& \cdot \frac{l_{\text {in }}}{w_{\text {in }} \cdot\left(\mathrm{th}_{\mathrm{in}}-R_{\mathrm{Al}-\mathrm{dep}} \cdot\left(t-t_{0}\right)\right)} \\
= & R_{\mathrm{cont}}+R_{\mathrm{in}} \\
& \cdot \frac{l_{\text {in }}}{1-\left(R_{\mathrm{Al}-\mathrm{dep}} / \mathrm{th}_{\mathrm{in}}\right) \cdot\left(t-t_{0}\right)},
\end{aligned}
$$

where $R_{\text {cont }}$ is the contact resistance due to the interface between the connecting wires and the aluminum thin film and to the intrinsic resistance of the micron-sized nickel wires entering the growth glass bottle; $\rho_{\mathrm{Al}}$ is the aluminum resistivity; $l_{\text {in }}$ is the initial length of the aluminum track; $w_{\text {in }}$ is its initial width; $\mathrm{th}_{\mathrm{in}}$ is its initial thickness; $R_{\mathrm{Al} \text {-dep }}$ is the assumed constant rate of aluminum depletion; and $t_{0}$ is the time when the aluminum-ion migration starts. In the last two steps of (2), the lateral consumption of the track is considered negligible compared to the thickness reduction. Furthermore, we supposed that the aluminum resistivity is independent of temperature.

Consistently with the previous results shown in Figure 2, in less than one hour (from minute 21 to about minute 73 ) the aluminum is exhausted. The final value of 73 minutes is extrapolated by taking the intersection of the blue line with the $x$-axis. The very good fit with a hyperbolic function confirms that the aluminum film is depleted at a constant rate, from the surface down to the substrate, with a regular ion flux from the aluminum track into the LDH nanoplatelets. Interestingly, the dynamics of the depletion process did not

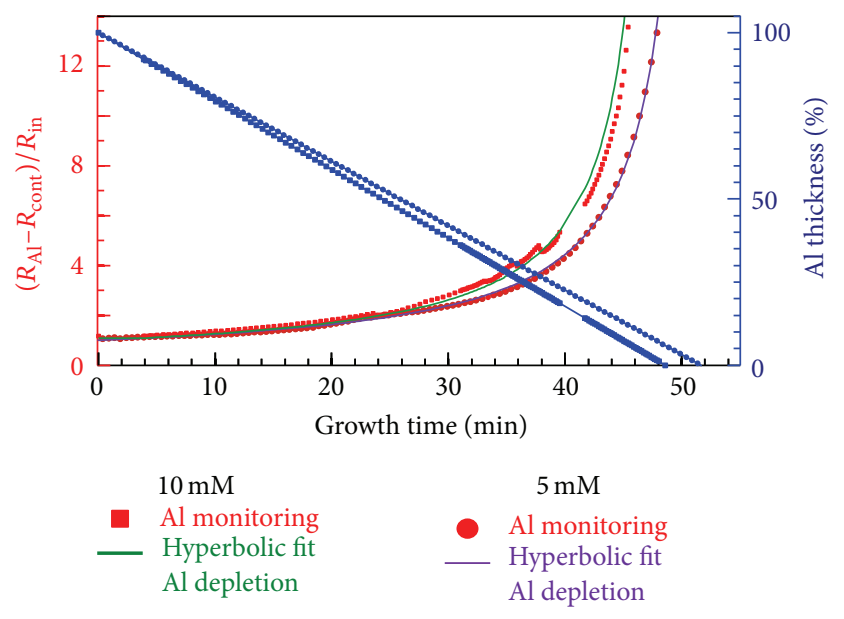

FIGURE 3: The electrical resistance of the aluminum microresistor as a function of the immersion time during the wet-chemical growth of LDH (purple dots). The continuous black line is a fit with a hyperbolic function of time according to (2). The blue line represents the aluminum thickness reduction.

change significantly, that is, with variations of parameters within $10 \%$, when monitoring was repeated by doubling the zinc equimolar concentration at $10 \mathrm{mM}$. As discussed in [29], the $\mathrm{ZnO}$ nanorods growth may occur, with the same recipe as the one presently used, only for bath temperatures higher than about $60^{\circ} \mathrm{C}$. On the other hand, as previously reported in [30], the LDH nanosheets can already be well formed at temperatures as low as $50^{\circ} \mathrm{C}$, thus suggesting that the $\mathrm{LDH}$ formation is energetically more favorable. Furthermore, in presence of aluminum, our results consistently show that the $\mathrm{LDH}$ growth greatly overcomes the $\mathrm{ZnO}$ formation. We also observed that, after about one hour of growth, when the aluminum track has already been consumed, the solution is still almost transparent (i.e., the $\mathrm{ZnO}$ formation in solution is also negligible); however, after some more time, the solution starts becoming milky colored because of the formation of $\mathrm{ZnO}$ nanostructures.

Next we consider the completely formed LDH which is shown in Figure 4 by SEM microphotographs (at different magnifications) of LDH samples grown for 12 hours onto predeposited aluminum layers with different initial thickness. It is evident that a nanostructured film has grown on the aluminum layer, with the nanoplatelets mostly oriented perpendicular to the surface, so that it exhibits a "cabbagelike" shape very similar to that reported in the literature $[16,24]$, by using comparable methods on thick aluminum foils, and to that obtained by our group $[6,22]$ on Alcoated silicon with a coating thickness higher than $25 \mathrm{~nm}$. However, even though in this case enough time is allowed, the limiting factor for the $\mathrm{LDH}$ growth is the aluminum content available over the substrate surface even in a low molarity zinc solution. In fact, the nanoplatelets exhibit a planar and well-formed lamellar-like shape, with a thickness greater than $100 \mathrm{~nm}$, only when the original aluminum layer is $300 \mathrm{~nm}$ thick at least (see Figure 4(c)). This effect is consistent with previous results [22] showing that the morphological quality 


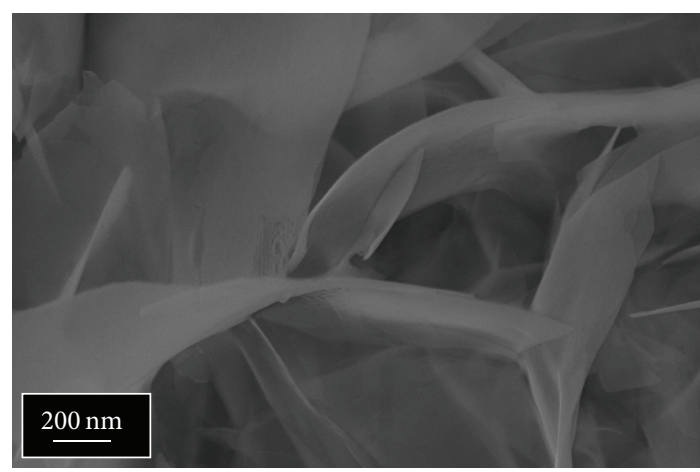

(a)

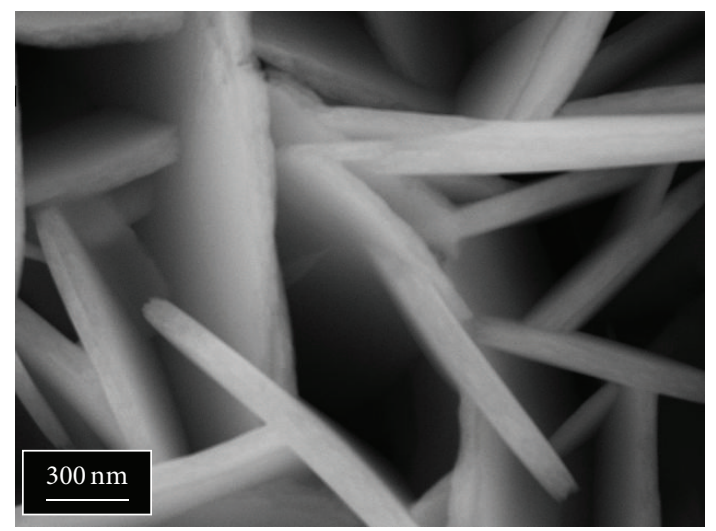

(c)

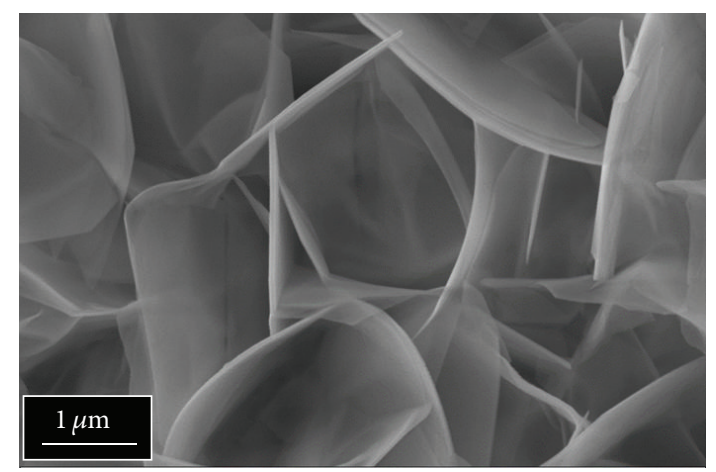

(b)

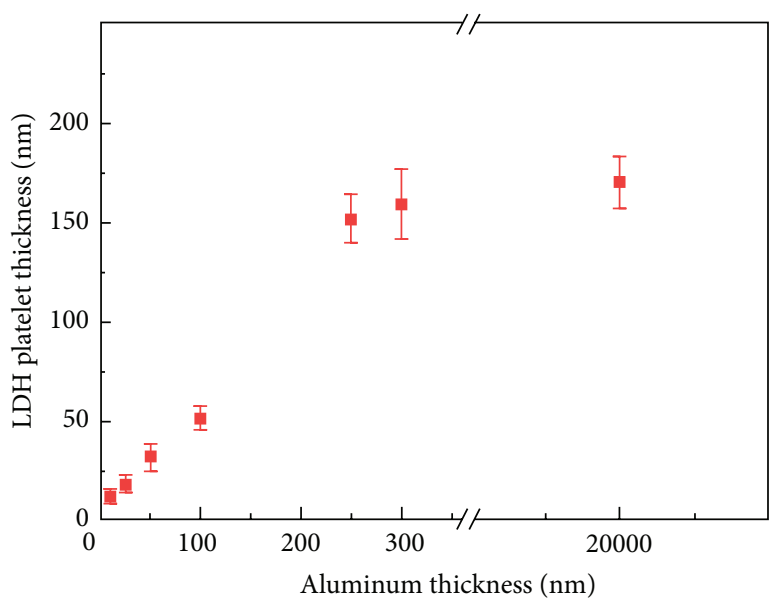

(d)

FIGURE 4: SEM images of the LDH nanoplatelets formed at $75^{\circ} \mathrm{C}$ with different aluminum layer thickness for a growth of $12 \mathrm{~h}$ : (a) $\mathrm{Al}$ thickness of $30 \mathrm{~nm}$; (b) Al thickness of $100 \mathrm{~nm}$; (c) ideally infinite Al thickness. (d) Mean value of LDH nanoplatelet thickness as a function of the original aluminum thickness (20 nanoplatelets measured for each point).

of LDH nanostructures increases with the thickness of the aluminum film in the range from 10 to $100 \mathrm{~nm}$. The process can be attributed to the achievement of the zinc/aluminum stoichiometric balance for the whole growth process, so that the LDH nanoplatelets can form with a more regular shape provided that enough aluminum is available.

The present data demonstrate that the nanoplatelet regularity and flatness keep improving with the aluminum thickness beyond $100 \mathrm{~nm}$ and very planar nanostructures are formed at thicknesses around $300 \mathrm{~nm}$ or higher. Moreover, by statistically measuring the dimensions of the deposited nanostructures we have found that the nanoplatelet thickness shows a strong positive linear correlation with the aluminum thickness in the range from $10 \mathrm{~nm}$ to $250 \mathrm{~nm}$, as reported in Figure 4(d). If the aluminum thickness is higher than $300 \mathrm{~nm}$, as in the case of bulk aluminum, the nanoplatelet thickness saturates to a value near $170 \mathrm{~nm}$. This indicates that the depletion of an aluminum layer down to a depth of $250 \mathrm{~nm}$, approximately, is sufficient to complete the growth of $\mathrm{LDH}$ flat nanoplatelets through the reaction with a $5 \mathrm{mM} \mathrm{Zn-}$ nitrate solution. In presence of a thinner aluminum coating, the LDH growth will stop at an earlier stage of formation, thus resulting in less flat and thinner $\mathrm{LDH}$ nanoplatelets.
Therefore, this effect allows having a certain control on the nanoplatelet morphology.

$\mathrm{X}$-ray diffraction and EDS provide further confirmations of a $(\mathrm{Zn}, \mathrm{Al}) \mathrm{LDH}$ structure similar to that reported in the literature $[16,24,31-33]$. Figure 5(a) shows the XRD spectrum of LDH nanoplatelets completely formed after a one-hour growth time (the same sample as in Figure 2(c)). Two basal reflections, (003) and (006), give evidence of parallel-oriented $\mathrm{LDH}$ nanoplatelets (not visible in the SEM image because of being covered by the vertical-oriented nanoplatelets). The $(00 l)$ reflections, in particular, allow directly determining the lattice parameter $c$, which gives the total thickness of the brucite-like layer plus an interlamellar space. The average value obtained for this sample is close to $22.64 \AA$, in good agreement with the values reported in literature $[1,16,24$, 30-32], also in consideration of the large variability of the interlamellar space, due to the different intercalated anions.

Moreover, the XRD pattern also shows the presence of some $(h k l)$ nonbasal reflections (i.e., having $h, k \neq 0$ ), coming from almost perpendicular-oriented nanoplatelets, which are visible in the SEM images, having the $c$-axis being almost parallel to the substrate (and parallel to the normal versor $\widehat{n}$ of 


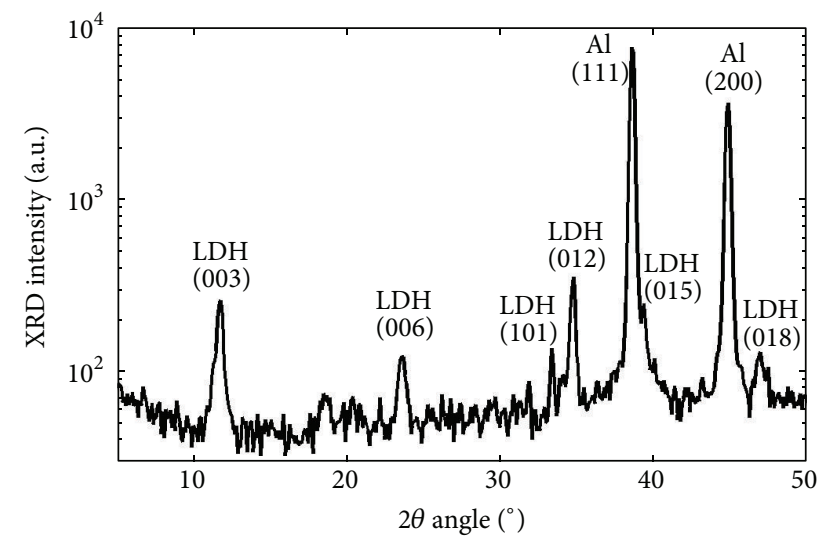

(a)

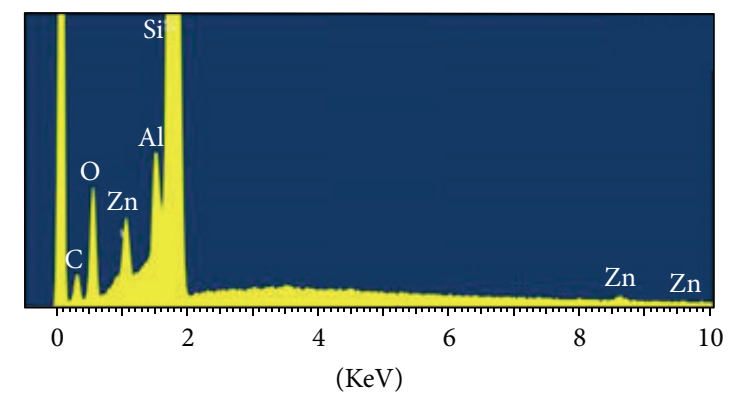

\begin{tabular}{ccc}
\hline Element & Weight (\%) & Atomic (\%) \\
\hline C K & 12.25 & 23.03 \\
O K & 10.99 & 15.51 \\
$\mathrm{Al} \mathrm{K}$ & 1.05 & 0.88 \\
$\mathrm{Si} \mathrm{K}$ & 75.13 & 60.39 \\
Zn K & 0.58 & 0.20 \\
\hline
\end{tabular}

(b)

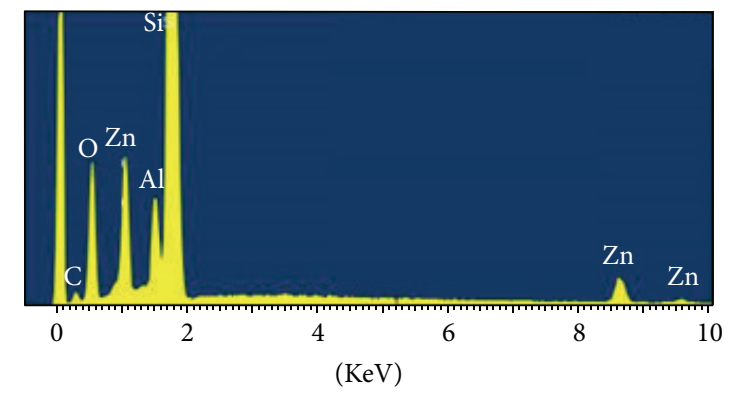

\begin{tabular}{ccc}
\hline Element & Weight (\%) & Atomic (\%) \\
\hline $\mathrm{C} \mathrm{K}$ & 7.32 & 14.10 \\
$\mathrm{O} \mathrm{K}$ & 20.65 & 29.86 \\
$\mathrm{Al} \mathrm{K}$ & 2.01 & 1.72 \\
$\mathrm{Si} \mathrm{K}$ & 62.84 & 51.77 \\
Zn K & 7.19 & 2.55 \\
\hline
\end{tabular}

(c)

FIGURE 5: (a) XRD 9-29 spectrum after complete growth. (b) EDS spectrum of a sample at the initial stage of growth time (15 minutes). (c) EDS spectrum of LDH after complete platelets formation $(1 \mathrm{~h})$.

Figure 1). By using the $c$-parameter experimentally obtained from symmetrical (001) reflections, we could calculate the $a$ lattice parameter, corresponding to the distance between two metal cations.

Specifically, the peak positions of the nonbasal reflections give a value of $a$ lattice parameter with an average value close to $3.062 \AA$ and a very small variance, in excellent agreement with the results reported in the literature for $(\mathrm{Zn}, \mathrm{Al}) \mathrm{LDH}$ $[1,16,24,31-33]$. Figure 5(b) reports the EDS spectrum of a sample at the initial stage of the growth (similar to the one as in Figure 2(a)). The chemical composition gives evidence of a great presence of aluminum (relative to zinc), coming from the underlying aluminum coating. Figure 5(c) shows the EDS of a well-formed sample, that is, with a growth time of 1 hour, with almost perpendicular-oriented nanoplatelets (similar to the one as in Figure 2(c)). In this case, the compositional analysis reveals a $\mathrm{Zn}: \mathrm{Al}$ ratio close to 3:2. An adhesion test was performed using ASTM D3359. The adhesion of the coating obtained was reasonably good, $3 \mathrm{~B}$, as rated by the standard.

Finally, we report on the precise spatial localization of the $\mathrm{LDH}$ growth allowed by the predeposited aluminum method, since this can be of great importance to engineer micro/nanodevices. As explained in the experimental section, we fabricated a pattern of 16 aluminum microresistors, shown in Figure 6(a), with each microresistor consisting in a serpentine of 16 lines with a $5 \mu \mathrm{m}$ width and spaced of the same distance (see Figure 6(b)). In this way, we found that, for higher resolution patterning, the initial Al film should be thinner. In fact, Figure 6(c) shows that when LDH grows onto a $300 \mathrm{~nm}$ thick aluminum layer, the growth is not restricted within the patterned tracks and the different LDH lines of the serpentine merge together, even though the original pattern is still visible. Conversely, if a much lower initial aluminum thickness is used (see Figure 6(d)), this effect does not take place and the growth is localized within the borders of the aluminum tracks with about $a \pm 0.5 \mu \mathrm{m}$ precision.

\section{Conclusions}

We have demonstrated that thewet-chemistry synthesis of LDHs by using reacting aluminum thin coatings deposited on silicon surface enables the growth of dense films of $\mathrm{LDH}$ nanoplatelets perpendicularly oriented to the substrate. The nanoplatelets start growing parallel to the substrate surface but in a short time begin to rotate and eventually they align perpendicular to it. We have also found that the final morphology takes less than one hour to be achieved. During this time, the required aluminum is depleted at a constant rate. Moreover, the morphology and, specifically, the thickness of nanoplatelets can be locally tuned by varying the thickness of the predeposited aluminum coating in the range $10-300 \mathrm{~nm}$. In fact, if the original aluminum layer thickness is lower than $250 \mathrm{~nm}$ the growth stops before the LDH nanostructures are fully formed, so that the nanoplatelet final thickness and shape are quite independent of the growth time and only linearly depend on the available aluminum thickness. Finally, provided that the aluminum initial thickness is low enough, the accurate localization of growth within the bounds of the aluminum layer can be achieved with an excellent spatial 


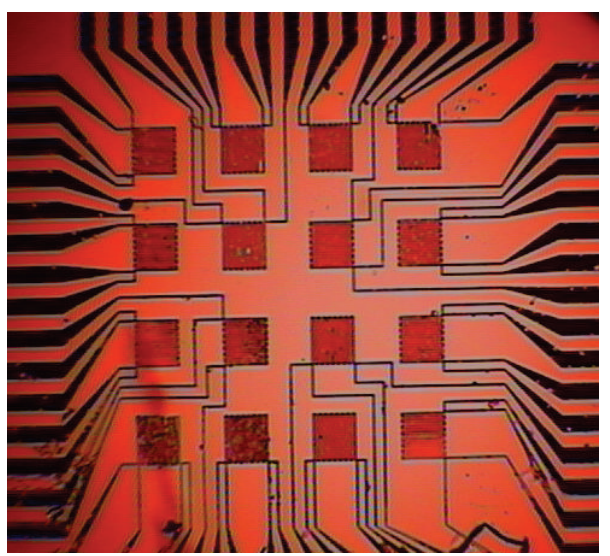

(a)

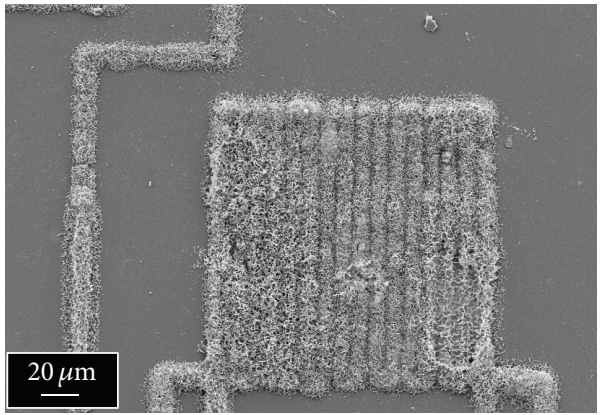

(c)

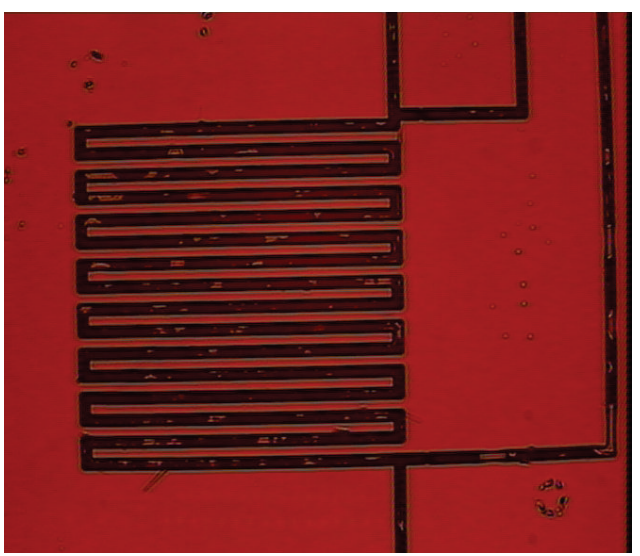

(b)

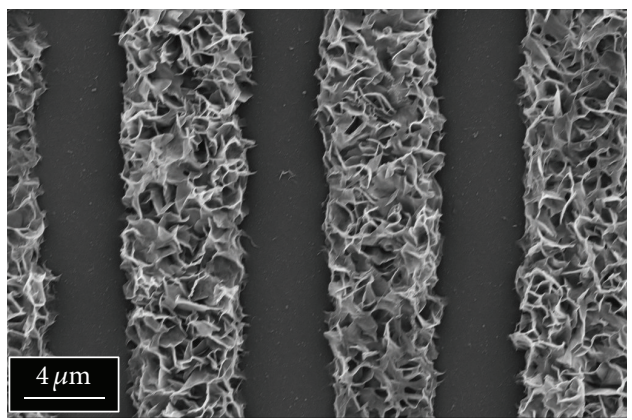

(d)

FiguRE 6: (a) Optical image of 16 aluminum microresistors micropatterned on glass substrate; (b) optical image of a single aluminum microresistor; (c) particular of a single LDH micro/nanoresistor deposited onto an aluminum thin film with a thickness of $300 \mathrm{~nm}$; (d) zoom of a LDH micro/nanoresistor deposited onto an aluminum thin film with a thickness of $30 \mathrm{~nm}$.

resolution (about $\pm 0.5 \mu \mathrm{m}$ ). Since the presented LDH wetchemistry recipe is fully compatible with the MEMS/CMOS technology, our results could be relevant for applications to integrated physical/chemical micro/nanodevices.

\section{Conflict of Interests}

The authors declare that there is no conflict of interests regarding the publication of this paper.

\section{References}

[1] A. Forano, T. Hibino, F. Lereoux, and C. Taviot-Guého, "Layered double hydroxide," in Handbook of Clay Science, F. Bergaya, B. Theng, and G. Lagaly, Eds., pp. 1021-1095, 2006.

[2] Q. Wang and D. O'Hare, "Recent advances in the synthesis and application of layered double hydroxide (LDH) nanosheets," Chemical Reviews, vol. 112, no. 7, pp. 4124-4155, 2012.

[3] X. Guo, F. Zhang, D. G. Evans, and X. Duan, "Layered double hydroxide films: synthesis, properties and applications," Chemical Communications, vol. 46, no. 29, pp. 5197-5210, 2010.

[4] Y. Kuang, L. Zhao, S. Zhang, F. Zhang, M. Dong, and S. Xu, "Morphologies, preparations and applications of layered double hydroxide micro-/nanostructures," Materials, vol. 3, no. 12, pp. 5220-5235, 2010.
[5] D. Shan, S. Cosnier, and C. Mousty, "HRP/[Zn-Cr-ABTS] redox clay-based biosensor: design and optimization for cyanide detection," Biosensors and Bioelectronics, vol. 20, no. 2, pp. 390396, 2004.

[6] A. Orsini, F. Gatta, C. Leonardi et al., "CMOS compatible, low power, high-sensitivity $\mathrm{Zn} / \mathrm{Al}$ layered double hydroxides humidity micro-sensor," in Sensors: Proceedings of the First National Conference on Sensors, Rome 15-17 February, 2012, F. Baldini, A. D’Amico, C. Di Natale et al., Eds., vol. 162 of Lecture Notes in Electrical Engineering, pp. 493-497, Springer, New York, NY, USA, 2014.

[7] Y. Lin, Q. Fang, and B. Chen, "Perchlorate uptake and molecular mechanisms by magnesium/aluminum carbonate layered double hydroxides and the calcined layered double hydroxides," Chemical Engineering Journal, vol. 237, pp. 38-46, 2014.

[8] R. Yang, Y. Gao, J. Wang, and Q. Wang, "Layered double hydroxide $(\mathrm{LDH})$ derived catalysts for simultaneous catalytic removal of soot and $\mathrm{NO}_{x}$," Dalton Transactions, vol. 43, no. 27, p. 10317, 2014.

[9] J. Han, D. Yan, W. Shi et al., "Layer-by-layer ultrathin films of azobenzene-containing polymer/layered double hydroxides with reversible photoresponsive behavior," Journal of Physical Chemistry B, vol. 114, no. 17, pp. 5678-5685, 2010.

[10] S. Cho, S. C. Hong, and S. Kim, "Quantum dot-layered double hydroxide composites for near-infrared emitting codes," Journal of Materials Chemistry C, vol. 2, no. 3, pp. 450-457, 2014. 
[11] J. Tedim, M. L. Zheludkevich, A. C. Bastos et al., "Effect of surface treatment on the performance of LDH conversion films," ECS Electrochemistry Letters, vol. 3, no. 1, pp. C4-C8, 2014.

[12] J. Tedim, M. L. Zheludkevich, A. N. Salak, A. Lisenkov, and M. G. S. Ferreira, "Nanostructured LDH-container layer with active protection functionality," Journal of Materials Chemistry, vol. 21, no. 39, pp. 15464-15470, 2011.

[13] D. Kubo, K. Tadanaga, A. Hayashi, and M. Tatsumisago, "Multifunctional inorganic electrode materials for high-performance rechargeable metal-air batteries," Journal of Materials Chemistry A, vol. 1, no. 23, pp. 6804-6809, 2013.

[14] E. L. Crepaldi, P. C. Pavan, and J. B. Valim, "Comparative study of the coprecipitation methods for the preparation of layered double hydroxides," Journal of the Brazilian Chemical Society, vol. 11, no. 1, pp. 64-70, 2000.

[15] E. Scavetta, B. Ballarin, and D. Tonelli, "Electrochemical behaviour of thin films of $\mathrm{Co} / \mathrm{Al}$ layered double hydroxide prepared by electrodeposition," Electrochimica Acta, vol. 54, no. 3, pp. 1027-1033, 2009.

[16] J. Liu, X. Huang, Y. Li, K. M. Sulieman, X. He, and F. Sun, "Facile and large-scale production of $\mathrm{ZnO} / \mathrm{Zn}-\mathrm{Al}$ layered double hydroxide hierarchical heterostructures," Journal of Physical Chemistry B, vol. 110, no. 43, pp. 21865-21872, 2006.

[17] X. Guo, S. Xu, L. Zhao et al., "One-step hydrothermal crystallization of a layered double hydroxide/alumina bilayer film on aluminum and its corrosion resistance properties," Langmuir, vol. 25, no. 17, pp. 9894-9897, 2009.

[18] J.-Y. Uan, J.-K. Lin, and Y.-S. Tung, "Direct growth of oriented $\mathrm{Mg}$-Al layered double hydroxide film on $\mathrm{Mg}$ alloy in aqueous $\mathrm{HCO}_{3}^{-} / \mathrm{CO}_{3}^{2-}$ solution," Journal of Materials Chemistry, vol. 20, no. 4, pp. 761-766, 2010.

[19] H. Chen, F. Zhang, S. Fu, and X. Duan, "In situ microstructure control of oriented layered double hydroxide monolayer films with curved hexagonal crystals as superhydrophobic materials," Advanced Materials, vol. 18, no. 23, pp. 3089-3093, 2006.

[20] J. Liu, Y. Li, X. Huang, G. Li, and Z. Li, "Layered double hydroxide nano- and microstructures grown directly on metal substrates and their calcined products for application as Li-ion battery electrodes," Advanced Functional Materials, vol. 18, no. 9, pp. 1448-1458, 2008.

[21] A. N. Salak, A. D. Lisenkov, M. L. Zheludkevich, and M. G. S. Ferreira, "Carbonate-free $\mathrm{Zn}-\mathrm{Al}(1: 1)$ layered double hydroxide film directly grown on zinc-aluminum alloy coating," ECS Electrochemistry Letters, vol. 3, no. 1, pp. C9-C11, 2013.

[22] D. Scarpellini, C. Falconi, P. Gaudio et al., "Morphology of $\mathrm{Zn} / \mathrm{Al}$ layered double hydroxide nanosheets grown onto aluminum thin films," Microelectronic Engineering, vol. 126, pp. 129-133, 2014.

[23] K. M. McPeak, T. P. Le, N. G. Britton, Z. S. Nickolov, Y. A. Elabd, and J. B. Baxter, "Chemical bath deposition of $\mathrm{ZnO}$ nanowires at near-neutral $\mathrm{pH}$ conditions without hexamethylenetetramine (HMTA): understanding the role of HMTA in $\mathrm{ZnO}$ nanowire growth," Langmuir, vol. 27, no. 7, pp. 3672-3677, 2011.

[24] Z. Lü, F. Zhang, X. Lei, L. Yang, S. Xu, and X. Duan, "In situ growth of layered double hydroxide films on anodic aluminum oxide/aluminum and its catalytic feature in aldol condensation of acetone," Chemical Engineering Science, vol. 63, no. 16, pp. 4055-4062, 2008.

[25] A. Orsini, F. Gatta, C. Leonardi et al., Sensors, vol. 162, Springer, New York, NY, USA, 2014, edited by: F. Baldini, A. D’Amico, C.
Di Natale, P. Siciliano, R. Seeber, L. de Stefano, R. Bizzarri, B. Andò.

[26] Y. Sun, "Watching nanoparticle kinetics in liquid," Materials Today, vol. 15, no. 4, pp. 140-147, 2012.

[27] J. M. Yuk, J. Park, P. Ercius et al., "High-resolution EM of colloidal nanocrystal growth using graphene liquid cells," Science, vol. 335, no. 6077, pp. 61-64, 2012.

[28] H.-G. Liao, L. Cui, S. Whitelam, and H. Zheng, "Real-time imaging of Pt3Fe nanorod growth in solution," Science, vol. 336, no. 6084, pp. 1011-1014, 2012.

[29] A. Orsini and C. Falconi, "Real-time monitoring of the solution growth of $\mathrm{ZnO}$ nanorods arrays by quartz microbalances and in-situ temperature sensors," Scientific Reports, vol. 4, article 6285,2014

[30] Y. F. Gao, M. Nagai, Y. Masuda, F. Sato, W. S. Seo, and K. Koumoto, "Surface precipitation of highly porous hydrotalcitelike film on Al from a zinc aqueous solution," Langmuir, vol. 22, no. 8, pp. 3521-3527, 2006.

[31] C. Coelho, T. Stimpfling, F. Leroux, and V. Verney, "Inorganicorganic hybrid materials based on amino acid modified hydrotalcites used as UV-absorber fillers for polybutylene succinate," European Journal of Inorganic Chemistry, no. 32, pp. 5252-5258, 2012.

[32] S. Newman and J. William, Supramolecular Organization Materials Design, edited by W. Jones and C. N. R. Rao, Cambridge University Press, 2008.

[33] A. N. Salak, J. Tedim, A. I. Kuznetsova et al., "Comparative Xray diffraction and infrared spectroscopy study of $\mathrm{Zn}$-Al layered double hydroxides: vanadate vs nitrate," Chemical Physics, vol. 397, no. 1, pp. 102-108, 2012. 

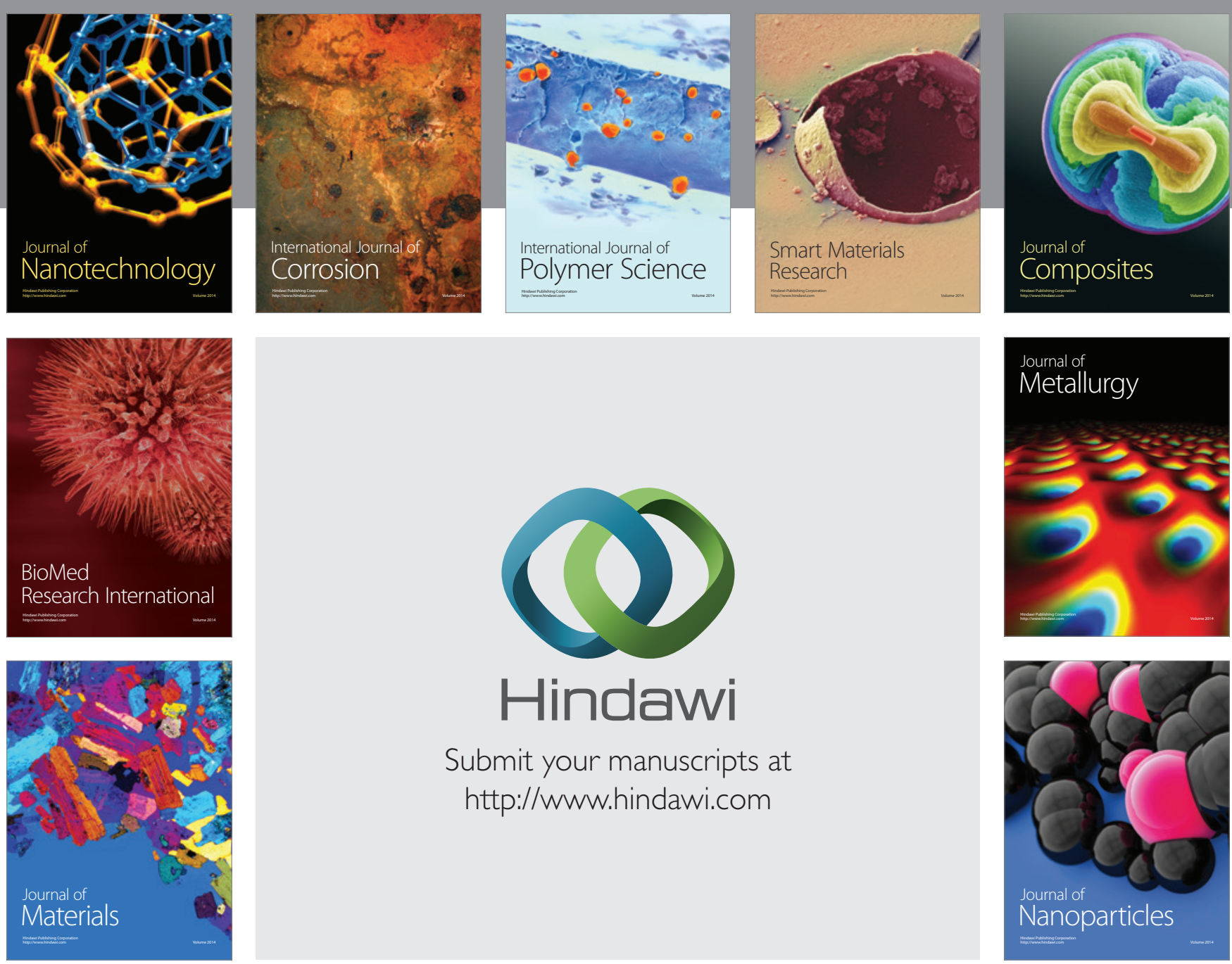

Submit your manuscripts at http://www.hindawi.com
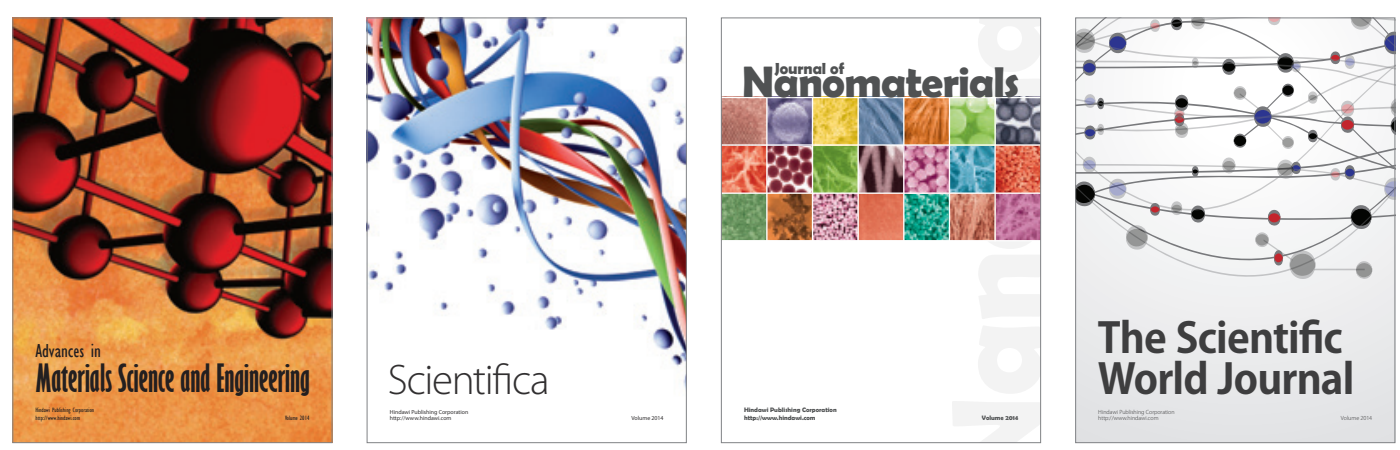

\section{The Scientific World Journal}
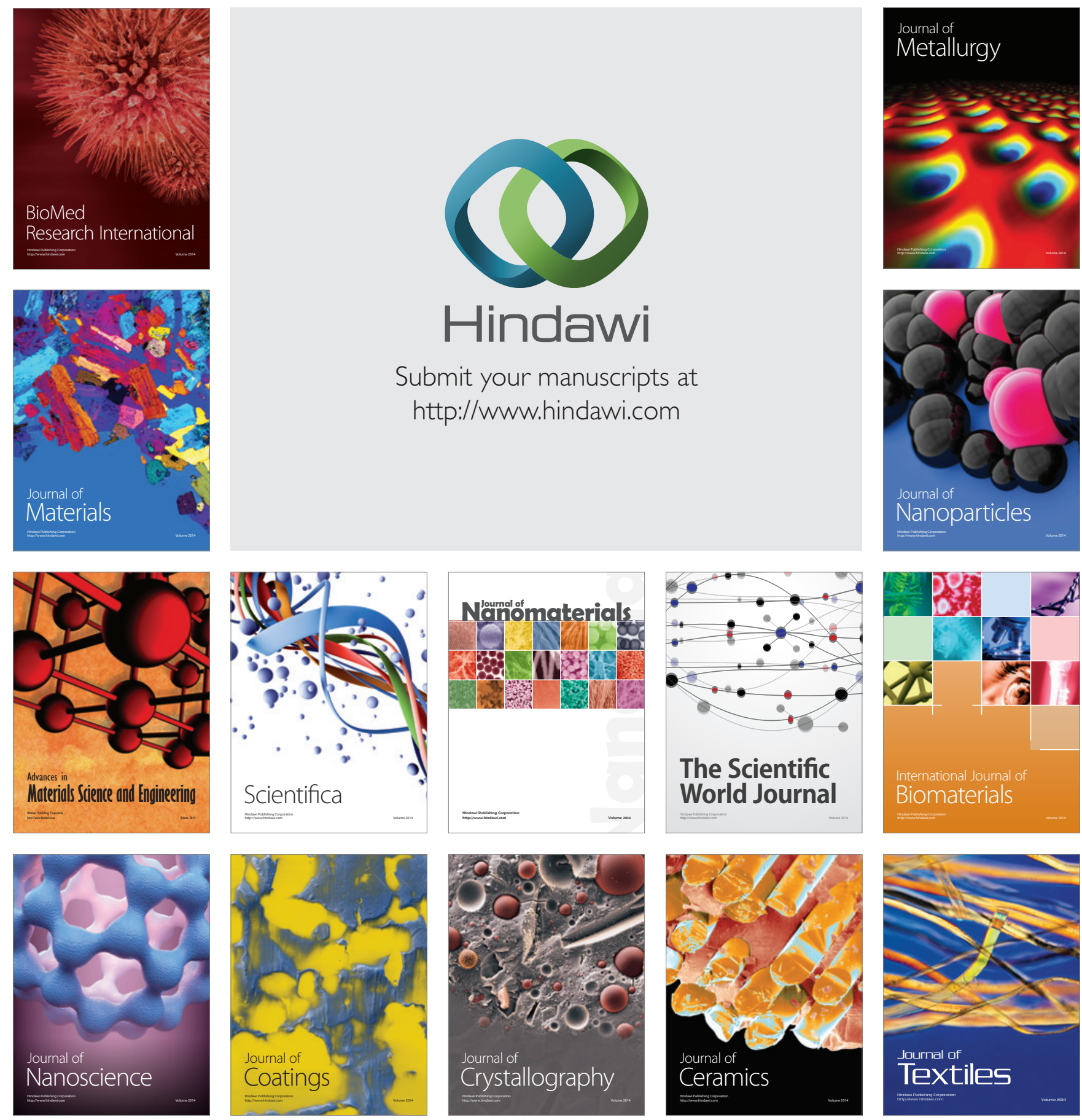